\title{
Psychopathy in women: theoretical and clinical perspectives
}

This article was published in the following Dove Press journal:

International Journal of Women's Health

30 May 2012

Number of times this article has been viewed

Rolf Wynn ${ }^{1,2}$

Marita H Høiseth'

Gunn Pettersen ${ }^{3}$

'Department of Forensic Psychiatry, Division of Addiction and Specialized Psychiatric Services, University Hospital of North Norway, Tromsø, Norway; ${ }^{2}$ Telemedicine Research Group, Department of Clinical Medicine, ${ }^{3}$ Department of Health and Care Sciences, Faculty of Health Sciences, University of Troms $\varnothing$, Norway
Correspondence: Rolf Wynn

Building 5, UNN-Åsgård,

N-929I Tromsø, Norway

Tel +47 77620888

Fax +47 77627532

Email rolf.wynn@gmail.com
Abstract: Prior research on psychopathy has primarily focused on the problem in men. Only a few studies have examined whether psychopathy even exists in women, and if so, how the disorder manifests itself in them. This paper presents a narrative review of the literature on gender and psychopathy. We briefly discuss why this is an important topic for women and we discuss its causes. The concept of psychopathy is defined and related to the diagnostic systems. The discussion includes a presentation of diagnostic tools, including the Hare Psychology Checklist - Revised, which are examined in relationship to the importance of biological gender. While emphasizing the similarities as well as the differences between the sexes, we discuss the matters of prevalence, behavioral expressions, comorbidity, progression, and treatment of the disorder.

Keywords: psychopathy, antisocial, dissocial, personality disorder, sex, women, review

\section{Introduction}

Psychopathy has primarily been studied in men. Relatively little research has examined whether psychopathy even exists in women, and if so, how the disorder manifests itself in them. This article provides a narrative review of the topic, which includes a synthesis of the literature on the sexes and psychopathy. We briefly discuss why this is also an important topic for women and we discuss its causes. We define the concept, place it in the diagnostic systems, and provide an overview of diagnostic procedures. In addition, while emphasizing the similarities and differences between the sexes, we discuss the matters of prevalence, behavioral expressions, comorbidity, progression, and treatment of the disorder.

\section{Why focus on psychopathy in women?}

Most studies on psychopathy have examined men with the disorder. They have assumed that the core characteristics and behavioral expressions of the disorder are transferable to women. ${ }^{1-3}$ While this is an important topic, for clinical and theoretical reasons, ${ }^{4}$ until recently, potential differences between the sexes have not received much scientific attention. The importance of the concept of "psychopathy" relates to its potential usefulness with regard to issues such as the choice of treatment strategies, treatment evaluation, risk assessment, and the prediction of future violence. ${ }^{5}$ If one assumes that the same research results achieved in studying men are automatically transferable to women, one does risk misjudgments of enormous consequence. For instance, within the field of forensic psychiatry, the diagnosis of psychopathy is often 
used to justify the length of prison terms; in some countries, indefinite prison terms can be given to criminals with this diagnosis. ${ }^{6}$ The diagnosis of psychopathy may also be used to justify patients' exclusion from treatment programs as well as other punitive measures.

\section{Causes of psychopathy}

Psychopathy cannot be understood solely as a result of social and environmental forces and influences. To a substantial degree, the condition is likely caused by genetic factors, which influence the formation of the brain and thus personality and temperament traits, which are believed to be the core characteristics of the disorder. ${ }^{7-11}$ However, it is likely that the development of psychopathy in an individual is the result of complex interactions between biological and temperamental predispositions as well as social and environmental influences. ${ }^{12}$ It has also been suggested that the underlying causes of psychopathy could be different in men and women. ${ }^{8,13-15}$

\section{Defining and placing the psychopathy construct in diagnostic systems}

As a clinical construct, a distinct pattern of emotional, interpersonal, and behavioral characteristics defines psychopathy. The literature often refers to psychopathy as a narrower diagnostic category than either antisocial personality disorder (Diagnostic and Statistical Manual of Mental Disorders IV [DSM-IV] ${ }^{16}$ ) or dissocial personality disorder (International Statistical Classification of Disease and Related Health Problems, 10th revision [ICD-10] $]^{17}$ ). Furthermore, it is often considered to be one of the most serious personality disorders. ${ }^{18,19}$ In addition to the low recovery rate, this consideration is also due to the extensive social and personal consequences that follow in the wake of the criminal behavior of psychopaths. The emotional characteristics of psychopathy include egocentricity, blunted affect, lack of empathy, lack of remorse, and lack of guilt. The interpersonal characteristics include impulsiveness, irresponsibility, arrogance, grandiosity, and manipulation. The behavioral characteristics include a lack of respect for social norms and rules and a display of irresponsible, frightening, and violent behavior. ${ }^{5,6,18}$ Psychopathy seems to exist in all cultures and ethnic groups. ${ }^{20}$

In modern psychopathy research, there are two distinct traditions: a behaviorist tradition and a personality-based approach. The American Psychiatric Association (APA) uses the behavioral approach in the diagnostic system DSM-IV; ${ }^{16}$ psychopathy falls under the diagnostic category 301.7: antisocial personality disorder. The diagnosis mainly includes behavioral concepts; although emotional traits are mentioned as associated characteristics, they are not included as required diagnostic criteria. ${ }^{16}$

The category, DSM-IV 301.7, includes a far larger group than the obvious psychopaths; furthermore, with its emphasis on antisocial characteristics, this diagnostic category will include most criminals. ${ }^{16,21}$ In contrast, there is an approach to psychopathy focusing on personality traits, and this personality-based theory is more firmly represented in the diagnostic system of the World Health Organization (WHO), the ICD-10. ${ }^{17}$ Dissocial personality disorder (ICD-10: F 60.2) is characterized by indifference toward social obligations and an expressed lack of empathy. There is a large discrepancy between behavior and social norms, and rules and obligations. The patient lacks the capacity to experience guilt. Negative experiences, such as punishment, do not particularly affect their behavior. In addition, the patient has a low tolerance for frustration and may easily become aggressive and violent. Moreover, "there is a tendency to blame others, or to provide plausible rationalizations for the behavior, bringing the patient into conflict with society." 17 The patient also typically lacks the ability to maintain lasting relationships. Behavioral problems in childhood and adolescence may support the diagnosis, but this is not an obligatory criterion. ${ }^{17}$

Neither dissocial personality disorder nor antisocial personality disorder fully cover the term "psychopathy," and even if the diagnoses have much in common, they are clearly not identical. About a third of the individuals who meet the criteria for antisocial personality disorder, will also meet the criteria for psychopathy. ${ }^{18,22}$ Because the ICD-10 diagnosis of dissocial personality disorder includes more criteria that involve emotions and interpersonal characteristics, it is probably closer to the concept of psychopathy than the DSM-IV diagnosis of antisocial personality disorder.

\section{Diagnosing psychopathy}

The most frequently used and validated diagnostic tool for assessing psychopathy is the Hare Psychopathy Checklist Revised (PCL-R). ${ }^{5}$ The PCL-R consists of 20 items, which are scored from 0 to 2 depending on how well each item fits an individual. Items include superficiality, lack of guilt and behavioral control, grandiosity, shallow affects, and a parasitic lifestyle. Other items are early behavioral problems and adolescent crime, lying, lack of empathy, lack of planning for the future, manipulation of others, impulsiveness and irresponsible behavior, and criminal diversity. ${ }^{5}$ The maximum score is 40, which is extremely rare. Within research, 30 is the accepted threshold for psychopathy, ${ }^{22}$ but a lower number (25) has been deemed more appropriate for clinical use 
in some cultures/countries, for instance in Scandinavia. ${ }^{6}$ In 1995, a revised form of the PCL-R was developed, a 12-item screening version, the Psychopathy Checklist: Screening Version (PCL: SV), ${ }^{23,24}$ to satisfy a clinical demand for a shorter screening tool. This screening version was developed in connection with the MacArthur Violence Risk Assessment Study $^{24}$ and like the PCL-R, it is scored on a scale from 0 to 2 , where a sum of 18 or more qualifies for the diagnosis "psychopath." The PCL-R is a proven solid measurement tool, and a good predictor of the probability for future violence and antisocial behavior, as well as the recidivism of criminal behavior. Metastudies, which have shown moderate to large effect sizes, have demonstrated this tendency. ${ }^{25-28}$ Similarly promising results have been demonstrated for the PCL: SV. ${ }^{29}$

Research on differences between the sexes has suggested that psychopathy is less frequent in women than in men. However, it is debated whether the observed differences in the occurrence of male and female psychopaths reflect actual physical differences in the frequency of psychopathy, or whether those differences reflect factors related to aspects of the diagnostic tools and the terminology used, which surface when these criteria for evaluating psychopathy are applied to women..$^{2-4,13}$ Notwithstanding, the most frequently used diagnostic tools were developed and used primarily in male populations. In order to understand the possible importance of the diagnostic tools in relationship to what extent men and women are diagnosed as psychopaths, we must examine what the instruments measure and consider their factor structure.

The psychopathy checklists (the PCL-R and the PCL: $\mathrm{SV}$ ) show a clear factor structure in which factor one reflects interpersonal and affective items, while factor two reflects an antisocial and criminal lifestyle. ${ }^{5,30}$ Although the two-factor structure has been replicated in several studies, ${ }^{23,31}$ some have suggested that a three-factor or even a four-factor model could be more appropriate. ${ }^{32,33}$ In the three-factor model, the original factor one was split into two new factors and the new factor three consisted of noncriminal items from the original factor two. ${ }^{32,33}$ The rationale for removing criminal items from the three-factor model was that criminal activity was not considered a core feature of psychopathy but rather a consequence of the disorder. ${ }^{32,33}$ However, other researchers believe that criminal activity is a central element of the psychopathy construct and have maintained the necessity of including criminal activity. ${ }^{34}$ Subsequently, a four-factor model has been proposed, involving splitting the original factor one (interpersonal, affective) and the original factor two (antisocial lifestyle) into four factors: interpersonal, affect, lifestyle, and antisocial..$^{34-36}$ The original factor one is considered stable and static, and the interpersonal facet includes characteristics such as superficiality, grandiosity, lying, and manipulation. The affective facet includes lack of guilt, shallow affects, lack of empathy, and lack of responsibility for one's actions. The original factor two seems to be more dynamic and potentially mutable, and it has been suggested that this factor is influenced by childhood experiences. ${ }^{9,12,15}$ The lifestyle facet involves a craving for stimulation, a parasitic lifestyle, lack of plans for the future, impulsiveness, and irresponsibility. The antisocial facet involves lack of behavioral control, early behavioral problems, adolescent crime, term violations, and criminal diversity. ${ }^{5,35,37-39}$ Two other items, promiscuous sexual behavior and multiple short-term relationships, do not load for any of the factors, but they do contribute to the total score in the PCL-R. ${ }^{35}$

Since research on factor structure, validity, and the reliability of the diagnostic psychopathy instruments (PCL-R and PCL: SV) has primarily involved men, ${ }^{40}$ there is less literature on women. Nonetheless, recent research has supported the claim that a three-factor model has a better fit than the original two-factor model for women. ${ }^{41-43}$ Studies have indeed suggested that the PCL-R and the PCL: SV are reliable instruments for measuring psychopathy in women, ${ }^{36,43}$ but it has also been suggested that the validity seems to be higher when the checklists are applied to men. ${ }^{40,44}$ The explanation for this finding may be that women have a lower prevalence of antisocial behavior and thus have a lower relapse rate.

\section{The prevalence of psychopathy in women and men}

It is assumed that psychopaths constitute approximately $0.5 \%-1 \%$ of the population, while as many as $20 \%-25 \%$ of prison populations qualify for the diagnosis. ${ }^{35,37}$ Psychopaths are thought to be responsible for over half of all serious crime. This is in addition to the considerable devastation they cause in the form of physical, psychological, and financial damage for people who have been exposed to them. ${ }^{6,45}$

Some studies have examined the prevalence of psychopathy in women. ${ }^{23,41,42,46,47}$ With few exceptions, ${ }^{23}$ studies have shown that there are more male psychopaths than female. That women score lower on the PCL-R than men has been a consistent finding in prison populations ${ }^{41,46}$ as well as the wider field of forensic psychiatry. ${ }^{47}$ Persistent findings in surveys of violent subjects, ${ }^{41}$ forensic psychiatric wards, ${ }^{47}$ and other patient groups, ${ }^{48}$ indicate that women typically do have a lower score than men both on the PCL-R and on the 
PCL: SV. The results from one population study showed that women had lower sum scores and subscale scores than men on the PCL: SV and that none of the women in the study met the criteria for psychopathy. ${ }^{49}$ However, a different study of prison inmates showed a minor significant difference in sum scores. ${ }^{50}$ In the manual of the PCL-R, ${ }^{5}$ the threshold for psychopathy is set at 30 points, and few women in the general population seem to achieve this score. Since women typically show less criminal and antisocial behavior, ie, the behavioral characteristics, which represent an important part of the criteria of the PCL-R and the PCL: SV, women will generally achieve lower scores on the diagnostic tools and therefore show lower occurrence rates. ${ }^{51-53}$ Furthermore, in select populations with a higher occurrence of behavioral problems and higher rates of criminal behavior, men more often qualify for the diagnosis than women. Grann ${ }^{47}$ found that only $11 \%$ of female violent subjects, as opposed to $31 \%$ of male violent subjects, met the criteria for psychopathy. Other studies found female occurrence rates of $16 \%{ }^{46}$ and $17.4 \%{ }^{42}$ in prison populations, ie, substantially lower rates than those found among men in prison.

\section{Behavioral expressions in women and men}

Forouzan and Cooke ${ }^{2}$ claim that there are differences between the sexes with respect to psychopathy. They suggest four key points in the way these differences manifest: (1) behavior, (2) interpersonal characteristics, (3) underlying psychological mechanisms, and (4) different social norms for men and women. Moreover, they claim that the behavior observed in the sexes differs both with regard to the manifestation of the psychopathic behavior and in the expression of interpersonal characteristics. As for the behavioral expression of the disorder, Forouzan and Cooke ${ }^{2}$ suggest that women who are manipulative more often tend to flirt, while manipulative men are more likely to run scams and commit fraud. In women, the tendency to run away, exhibit self-injurious behavior, and manipulation, all characterize impulsiveness and behavioral problems. Moreover, their criminal behavior consists primarily of theft and fraud. In men, however, the criminal behavior often includes violence. ${ }^{11,24}$ Indeed, the form of aggression that is displayed appears to differ between the sexes. Although the results are divergent and inconclusive, ${ }^{54}$ some studies have suggested that while men more often show physical aggression, ${ }^{45,55}$ women more often display a more relational and verbal form of aggression. ${ }^{51,52,56}$ This may, for instance, occur through manipulation of social networks in attempting to exclude the victim from a community. Alternatively, it may take the form of threats of self injury, with consequences for family and friends. Furthermore, the interpersonal symptoms in female psychopaths are not particularly characterized by superficial charm and a grandiose self-image, as is the case with men. ${ }^{3}$ This could possibly be related to cultural conditions and childhood circumstances. As for underlying psychological conditions, it has been suggested that typical markers for psychopathy, such as promiscuous behavior, may have different underlying motivational factors in men and women. ${ }^{2}$ For instance, promiscuity in female psychopaths may reflect a wish to gain financial or social benefits. ${ }^{19}$ Finally, it is suggested that social norms may influence the evaluation of certain psychopathic characteristics differently in men and women. ${ }^{1-3}$ For instance, in the West, it is accepted socially and culturally that a woman depends financially on her husband, while a man doing the same thing more easily could be seen as indulging in "parasitic behavior."2

\section{Diagnostic comorbidity of women and men with psychopathy}

Female inmates frequently show more Axis 1 symptoms than females in the general population or male inmates. They are clearly diagnosed more often with an emotionally unstable personality disorder and less often with an antisocial personality disorder. ${ }^{22}$ Despite this, few studies have examined the connection between psychopathy in women and comorbidity; nonetheless, the studies that have been performed seem to indicate that there is a similar pattern in men and women. ${ }^{42}$ The most prevalent disorder in both sexes is antisocial personality disorder, while in women there is also a strong comorbidity with all cluster B personality disorders. In both sexes, there is a clear connection between psychopathy and alcohol and drug abuse.

\section{Progression of the disorder in women and men}

It has been suggested that the disorder has a different progression in men and women with regard to both onset and expression. The familiar understanding of the progression, in which early behavioral problems and antisocial behavior during childhood are associated with psychopathy, ${ }^{12,57}$ seems to be most relevant for men. For women, the picture appears to be somewhat different since the behavioral problems of many in this group seem to arise first in adolescence. ${ }^{14}$ The antisocial behavior of the young women may also have a different expression than in the young men. ${ }^{14}$ It has been suggested that early criminal tendencies, rule violations, 
physical aggression, and violence are good predictors of psychopathic development in young men. ${ }^{9}{ }^{12,19}$ At this same stage, young women, who later develop the disorder, show a more relational form of aggression characterized by jealousy, self-harm, manipulation, and verbal aggression. The exception is a small subcategory of young women who share the same tendencies as young men with behavioral problems, but with a later onset than what is typical in young men. ${ }^{14}$

\section{Treatment of the disorder in women and men}

Studies on the treatment of psychopathy have primarily focused on men. ${ }^{1,13,43}$ Drawing on these studies, it is clear that psychopaths of both sexes are often regarded as a considerable violent risk and they generally respond poorly to treatment. The fact that psychopathy is a solid predictor of both harmful behavior and violence seems to be beyond question. However, responsiveness to treatment is a more controversial matter. ${ }^{11,19}$ Research seems to indicate that those with a high PCL-R score get little benefit from the treatment and interventions, which may be suited for others, and that such treatment, in some cases, may even have a negative effect. ${ }^{58}$ Evaluation of the treatment response in this subgroup reveals little effect of the measures taken to increase empathy, conscience, and interpersonal skills, or those targeting feelings of low self-esteem, anxiety, and depression. ${ }^{19}$ In spite of this, there is no evidence to suggest that all types of treatment are useless. Considering the components of the disorder, factor one seems static and rigid, and factor two seems more dynamic and potentially impressionable. Accordingly, research indicates that treatment should focus on preventing violence and other more specific negative behaviors. ${ }^{6}{ }^{6}$ It is important to consider that criminals with psychopathic tendencies are not a homogenous group. The prototype of a psychopath will score high on all four facets (interpersonal, affect, lifestyle, and antisocial), while patients with more limited symptomatology, such as many women diagnosed with this disorder, ${ }^{41,47-50}$ typically score high on fewer of the facets. For instance, a psychopathic patient with primarily manipulative tendencies may score high on the facets lifestyle and antisocial. ${ }^{19,35}$ As a result of these varying facet scores, it may seem appropriate to target the different types of psychopathic patients with different and more individually adjusted treatment programs. Some of these patients will, in all probability, profit from a number of different treatment programs, while others may prove particularly resistant to treatment. ${ }^{19}$ Consequently, it does not seem appropriate to offer treatment targeted at developing empathy to psychopaths with high scores in the affective facet unless there is the belief that the underlying personality can be altered. Neither does treatment directed at anger management seem appropriate for the majority of psychopaths, since the violence they perform usually is not a result of overwhelming emotions, but more often an instrumental type of violence, which is planned, nonemotional, and motivated by external objectives. ${ }^{19,35}$ Follow-up has proved important to reduce the risk of violence, and the MacArthur study revealed that those with close and frequent supervision while on parole had a significantly lower chance of recidivism. ${ }^{36} \mathrm{~A}$ central element in the treatment should be to reduce substance abuse, remove the association with negative (ie, criminal) networks, and alter behavior. In addition to performing a good analysis of what motivates a particular individual to change, this may, for instance, be achieved by making social behavior pay and antisocial behavior not pay. ${ }^{19}$

\section{Conclusion}

In this narrative review, we presented a synthesis of the literature on the sexes and psychopathy. We demonstrated that the topic is also of importance with respect to women and that a lack of focus on this disorder may have negative implications. We pointed out that the development of psychopathy in women and men is the result of complex interactions between biological and temperamental predispositions, and social and environmental influences. ${ }^{12}$ We defined psychopathy and placed it in relation to the DSM-IV diagnosis of antisocial personality disorder and the ICD-10 diagnosis of dissocial personality disorder. In presenting the commonly used diagnostic instruments PCL-R and PCL-SV, we discussed how sex may be a factor of importance to the results achieved using these and comparable tools. Although psychopathy occurs more frequently and typically more severely in men, we additionally discussed literature that showed that the problem also exists in women. Clinicians should be aware that the behavioral expression of the disorder might differ between women and men. Female sufferers more often seem to show emotional instability, verbal violence, and manipulation of social networks, and, to a lesser degree than male psychopaths, criminal behavior and instrumental violence. ${ }^{43}$ Finally, we discussed the aspects of comorbidity, progression, and treatment, pointing out that while there are many similarities, important sex-related differences do exist and should be considered.

\section{Disclosure}

The authors report no conflicts of interest in this work. 


\section{References}

1. Cale EM, Lilienfeld SO. Sex differences in psychopathy and antisocial personality disorder. A review and integration. Clin Psychol Today. 2002;22:1179-1207.

2. Forouzan E, Cooke DJ. Figuring out la femme fatale: conceptual and assessment issues concerning psychopathy in females. Behav Sci Law. 2005;23:765-778.

3. Rogstad JE, Rogers R. Gender differences in contributions of emotions to psychopathy and antisocial personality disorder. Clin Psychol Rev. 2008;28:1472-1484.

4. Jackson R, Richards H. Psychopathy in women: a valid construct with clear implications. In: Herve H, Yuille JC, editors. The Psychopath: Theory, Research, and Practice. Mahwah, NJ: Erlbaum; 2007: 389-410.

5. Hare RD. Manual for the Hare Psychopathy Checklist-Revised. 2nd ed. Toronto, ON, Canada, Multi-Health System; 2003.

6. Rosenqvist R, Rasmussen K. Rettspsykiatri i praksis, 2 utg [Forensic Psychiatry in Practice, 2nd ed]. Oslo, Norway: Universitetsforlaget; 2004. Norwegian.

7. Raine A, Lee L, Yang Y, Colletti P. Neurodevelopmental marker for limbic maldevelopment in antisocial personality disorder and psychopathy. Br J Psychiatry. 2010;197:186-192.

8. Blonigen DM, Hicks BM, Kruger RF, Patrick CJ, Lacono WG. Psychopathic personality traits: heritability and genetic overlap with internalizing and externalizing psychopathology. Psychol Med. 2005;35(5):637-648.

9. Waldman ID, Rhee SH. Genetic and environmental influences on psychopathy and antisocial behavior. In: Patric CJ, editor. Handbook of Psychopathy. New York, NY: Guilford Press; 2006:205-228.

10. Viding E, Blair RJ, Moffitt TE, Plomin R. Evidence for substantial genetic risk for psychopathy in 7-year-olds. J Child Psychol Psychiatry. 2005;46(6):592-597.

11. Harris GT, Rice ME, Hilton Z, Lalumiere L, Quinsey VL. Coercive and precocious sexuality as a fundamental aspect of psychopathy. J Pers Disord. 2007;21(1):1-27.

12. MacDonald AW, Iacono WG. Toward an integrated perspective on the etiology of psychopathy. In: Patric CJ, editor. Handbook of Psychopathy. New York, NY: Guilford Press; 2006:375-388.

13. Nicholls TL, Petrila J. Gender and psychopathy: an overview of important issues and introduction to the special issue. Behav Sci Law. 2005;23:729-741.

14. Verona E, Vitale J. Psychopathy in women: assessment, manifestations and etiology. In Patric CJ, editor. Handbook of Psychopathy. New York, NY: Guilford Press; 2006:415-436.

15. Bernstein DP, Stein JA, Handelsman L. Predicting personality pathology among adult patients with substance use disorders: effects of childhood maltreatment. Addict Behav. 1998;23(6):855-868.

16. American Psychiatric Association. Diagnostic and Statistical Manual of Mental Disorders - Text Revision. 4th ed. Washington, DC: American Psychiatric Association; 2000.

17. World Health Organization. International statistical classification of diseases and related health problems 10th revision. Available from: http://apps.who.int/classifications/apps/icd/icd10online/. Accessed December 10, 2011.

18. Hart SD, Hare RD. Psychopathy and antisocial personality disorder. Curr Opin Psychiatry. 1996;9:129-132.

19. Thornton D, Blud L. The influence of psychopathic traits on response to treatment. In: Herve H, Yuille JC, editors. The Psychopath: Theory, Research and Practice. Mahwah, NJ, Lawrence Erlbaum Associates; 2007:505-539.

20. Murphy JM. Psychiatric labeling in cross-cultural perspective. Science. 1976;191:1019-1028.

21. Lykken DT. The Antisocial Personalities. Hillsdale, NJ: Lawrence Erlbaum Associates; 1995.

22. Hare RD, Hart SD, Harpur TL. Psychopathy and the DSM-IV criteria for antisocial personality disorder. J Abnorm Psychol. 1991;100(3): 391-398.
23. Hart SD, Cox DN, Hare RD. Manual for the Psychopathy Checklist: Screening Version (PCL: SV). Toronto, ON: Multi-Health System; 1995.

24. Skeem JL, Mulvey EP. Psychopathy and community violence among civil psychiatric patients: results from the MacArthur Violence Risk Assessment Study. J Clin Consult Psychol. 2001;69(3):358-374.

25. Walters GD. Predicting institutional adjustment and recidivism with the Psychopathy Checklist factor scores: a meta-analysis. Law Hum Behav. 2003;27:541-558.

26. Leistico AMR, Salkin RT, DeCoster J, Rogers R. A large scale metaanalysis relating the Hare measures of psychopathy to antisocial conduct. Law Hum Behav. 2008;32:28-45.

27. Salekin RT, Rogers R, Sewell KW. A review and meta-analysis of the Psychopathy Checklist and Psychopathy Checklist-Revised: Predictive validity of dangerousness. Clin Psychol Sci Pract. 1996;3(3):203-215.

28. Hemphill JF, Hare RD. Psychopathy checklist factor scores and recidivism. Issues in Criminological and Legal Psychology. 1996;24:68-73.

29. Huchzermeier C, Bruss E, Geiger F, Kernbichler A, Aldenhoff J. Predictive validity of the psychopathy checklist: screening version for intramural behaviour in violent offenders - a prospective study at a secure psychiatric hospital in Germany. Can J Psychiatry. 2008;53(6): 384-391.

30. Hare RD. A research scale for the assessment of psychopathy in criminal populations. Personality Individ Diff. 1980;1:111-119.

31. Brandt JR, Kennedy WA, Patrick CJ, Curtin JJ. Assessment of psychopathy in a population of incarcerated adolescent offenders. Psychol Assess. 1997;9:429-435.

32. Cooke DJ, Michie C, Hart SD. Facets of clinical psychopathy: toward clearer measurement. In Patric CJ, editor. Handbook of Psychopathy. New York, NY: Guilford Press; 2006:91-106.

33. Walters GD, Knight RA, Grann M, Dahle K-P. Incremental validity of the Psychopathy Checklist facet scores: predicting release outcome in six samples. J Abnorm Psychol. 2008;117(2):396-405.

34. Neumann CS, Kosson DS, Salekin RT. Exploratory and confirmatory factor analysis of the psychopathy construct: methodological and conceptual issues. In: Herve H, Yuille JC, editors. The Psychopath: Theory, Research and Practice. Mahwah, NJ, Erlbaum; 2007:79-104.

35. Hare RD. Psychopathy: a clinical and forensic overview. Psychiatr Clin North Am. 2006;29:709-724.

36. Neumann CS, Hare RD. Psychopathic traits in a large community sample: links to violence, alcohol use, and intelligence. J Consult Clin Psychol. 2008;76(5):893-899.

37. Neumann CS, Hare RD, Newman JP. The superordinate nature of psychopathy. J Pers Disord. 2007;21:102-117.

38. Hare RD, Neumann CS. Structural models of psychopathy. Curr Psychiatry Rep. 2005; 7:57-64.

39. Neumann CS, Vitacco MJ, Hare RD, Wuppermann MS. Reconstruing the reconstruction of psychopathy: a comment on Cooke, Michie, Hart, and Clark. J Pers Disord. 2005;19(6):624-640.

40. Singh JP, Grann M, Fazel S. A comparative study of violence risk assessment tools: a systematic review and metaregression analysis of 68 studies involving 25,980 participants. Clin Psychol Rev. 2011;31: 499-513.

41. Jackson RL, Rogers R, Neumann CS, Lambert PL. Psychopathy in female offenders: an investigation of its underlying dimensions. Crim Justice Behav. 2002;29:692-704.

42. Warren JI, Burnette ML, South SC, et al. Psychopathy in women: structural modeling and comorbidity. Int J Law Psychiatry. 2003; 26(3):223-242.

43. Dolan M, Vøllm B. Antisocial personality disorder and psychopathy in women: a literature review on the reliability and validity of assessment instruments. Int J Law Psychiatry. 2009;32:2-9.

44. Salekin RT, Rogers R, Ustad KL, Sewell KW. Psychopathy and recidivism among female inmates. Law Hum Behav. 1998;22(1):109-128. 
45. Bailey BA. Partner violence during pregnancy: prevalence, effects, screening, and management. Int J Womens Health. 2010;2:183-197.

46. Salekin RT, Rogers R, Sewell KW. Construct validity of psychopathy in female offender sample: a multitrait-multimethod evaluation. JAbnorm Psychol. 1997;106(4):576-585.

47. Grann M. The PCL-R and gender. Eur J Psychol Assess. 2000;16: 147-149.

48. Rutherford MJ, Cacciola JS, Alterman AI, McKay JR. Reliability and validity of the Revised Psychopathy Checklist in women methadone patients. Assessment. 1996;3:43-54.

49. Forth AE, Brown SL, Hart SD, Hare RD. The assessment of psychopathy in male and female noncriminals: reliability and validity. Person Individ Diff. 2006;20(5):531-543.

50. Douglas KS, Strand S, Belfrage H, Fransson G, Levander S. Reliability and validity evaluation of the Psychopathy Checklist Screening Version (PCL: SV) in Swedish correctional and forensic psychiatric samples. Assessment. 2005;12(2):145-161.

51. Carroll JS, Nelson DA, Yorgason JB, Harper JM, Ashton RH, Jensen AC Relational aggression in marriage. Aggress Behav. 2010;36:315-329.
52. Crick NR. Relational aggression: the role of intent attributions, feelings of distress, and provocation type. Dev Psychopathol. 1995;7: 313-322.

53. Penney SR, Moretti MM. The relation of psychopathy to concurrent aggression and antisocial behavior in high-risk adolescent girls and boys. Behav Sci Law. 2007;25:21-41.

54. Wynn R, Bratlid T. Staff's experiences with patients' assaults in a Norwegian psychiatric university hospital. A pilot study. Scand J Caring Sci. 1998;12:89-93.

55. Beasley JO. Serial murder in America: case studies of seven offenders. Behav Sci Law. 2004;22:395-414.

56. Kistner J, Counts-Allan C, Dunkel S, Drew CH, David-Ferdon C, Lopez C. Sex differences in relational and overt aggression in the late elementary school years. Aggress Behav. 2010;36:282-291.

57. Simonoff E, Elander J, Holmshaw J, Pickles A, Murray R, Rutter M Predictors of antisocial personality. Br J Psychiatry. 2004;184: $118-127$.

58. Salekin RT. Psychopathy and therapeutic pessimism: clinical lore or clinical reality? Clin Psychol Rev. 2002;22(1):79-112.
International Journal of Women's Health

\section{Publish your work in this journal}

The International Journal of Women's Health is an international, peerreviewed open-access journal publishing original research, reports, reviews and commentaries on all aspects of women's healthcare including gynecology, obstetrics, and breast cancer. Subject areas include: Chronic conditions (migraine headaches, arthritis, osteoporosis);

\section{Dovepress}

Endocrine and autoimmune syndromes; Sexual and reproductive health; Psychological and psychosocial conditions. The manuscript management system is completely online and includes a very quick and fair peer-review system. Visit http://www.dovepress.com/ testimonials.php to read real quotes from published authors.

Submit your manuscript here: http://www.dovepress.com/international-journal-of-womens-health-journal 